\title{
Examining the Relationship Between Motivations and Resilience in Different International Student Groups Attending U.S. Universities
}

\author{
Heba Mostafa \\ Yongsun Lim
}

Saint Louis University, USA

\begin{abstract}
Advancing diversity and inclusion in the U.S. higher education requires a solid understanding of the dynamics of students' mobility. This study investigated the intrinsic and extrinsic motivations that lead different international student groups to study in American universities, in connection with their resilience in overcoming the inevitable higher education challenges. An online survey was completed by 164 international students at three research universities. Pearson correlation coefficient analyses and independent $t$ tests were conducted to examine the relationships among three variables - intrinsic motivation, extrinsic motivation, and resilience - along with the differences among groups. Results show a medium-sized positive significant relationship between international students' intrinsic motivations and resilience, and significant differences among groups of students in relation to intrinsic and extrinsic motivations.
\end{abstract}

Keywords: extrinsic motivation, higher education, international students, intrinsic motivation, resilience

\section{INTRODUCTION}

The growing number of international students in the United States has had profound economic and cultural effects on American higher education institutions (HEIs) (Bowman \& Park, 2014; Chang, 1999; Chang et al., 2006; Franklin, 2013; Urban \& Palmer, 2016). International student enrollment in U.S. universities increased by $88 \%$ 
between school years 2006-2007 and 2017-2018, reaching 1,094,792 students (Institute of International Education [IIE], 2018). In the era of globalization, U.S. HEIs are making great efforts to retain international students and enhance their experience (Amirali \& Bakken, 2015). International students are considered "rich natural resources for developing global competency in U.S. higher education" (Siczek, 2015, p. 5). In addition, as argued by Johnson and Banks (2017), the presence of international students provides U.S. campuses with a finer understanding of the world and its cultures and is one of "the most powerful tools of diplomacy and development we have" (p. 55).

International students in the United States face various academic (Stanley \& Bhuvaneswari, 2016) and nonacademic challenges (Edwards et al., 2016) that influence their adjustment and well-being as they navigate their diverse American university contexts. These stressors are related to the relationships, anxiety, mood, and adjustment of international students (Hwang et al., 2014). However, individuals who have high levels of resilience are less influenced by adverse experiences, and function mostly normally (Edwards et al., 2016). Further, various sources of motivation, such as career advancement, social mobility, and personal growth (Hazen \& Alberts, 2006; Lesjak et al., 2015; Urban \& Palmer, 2016; Zhou, 2015), assist international graduate students to persist in overcoming the challenges they face in academia.

Given the growing trend of international student enrollment on U.S. campuses and the inevitable challenges that this group of students encounter, understanding their mobility dynamics, including their motives, experiences, and resilience traits, is one way to develop an "empowering learning culture" in U.S. universities (Guo \& Jamal, 2007, p. 40). Addressing issues related to student well-being and retention can promote an empowering learning culture for students from diverse racial and ethnic backgrounds (Guo \& Jamal, 2007).

This study used quantitative methodology to examine the relationship between the intrinsic motivation (IM), extrinsic motivation (EM), and resilience of different international student groups attending U.S. universities. The study aims to provide direction for higher education leaders about the dynamics of international students' mobility by identifying the interplay between international students' motives (whether intrinsic or extrinsic) and their resilience. The resulting implications will contribute to the globalization efforts of American higher education and the education of its diverse students.

\section{LITERATURE REVIEW}

\section{Diversity and Multiculturalism in Higher Education}

Defining diversity is a challenging task. The same student body can be perceived as more or less diverse depending on the perspectives on diversity held by the perceiver (for instance, by faculty and administrators) and the demographic makeup of the region (Valentine et al., 2012). In essence, diversity refers to heterogeneity or "all of the characteristics that make individuals different from each other" (Williams, 2013, p. 68). 
Diversity and multiculturalism are not synonyms for the same notion: While diversity refers to structural diversity, especially in relation to race, age, and sexual orientation, as explained by Williams (2013), the notion of multiculturalism represents an approach to public policy, education, and other social areas that support the cultural diversity of a multicultural and multiracial society. It describes the judgments, attitudes, controversies, and policy concerns that shape how diverse cultures are presented and identified (Chow, 2019).

In the United States, a large body of research has linked diversity in the educational environment with a broad range of positive outcomes for students, HEIs, and society as a whole (Bowman \& Park, 2014; Chang, 1999; Chang et al., 2006; Franklin, 2013). For instance, Chang et al. (2006) argued that racial diversity in HEIs can create a rich learning and social environment that supports students' learning and development. In addition, the U.S. regions that have universities with diverse student populations tend to show economic advantages over those with less diverse student bodies (Franklin, 2013). Many international students are motivated to study at U.S. universities for various reasons, including immigration to and employment in the United States (Zhou, 2015). One role of HEIs is to produce human capital; therefore, racial and ethnic diversity within HEIs transmits economic benefits to their regions and the firms within them (Franklin, 2013). At the university level, HEIs with racially diverse student bodies have a positive influence on students' overall satisfaction with college and on their social and intellectual self-confidence and university retention (Chang, 1999).

However, even after considerable research into the influence of diversity on higher education and its implications for students' development (Bowman \& Park, 2014; Chang et al., 2006; Franklin, 2013), issues related to the retention of minority students, and especially international students in the United States, have not been well addressed holistically. There is a gap in the current literature regarding the mobility dynamics of international students in the United States, specifically in relation to the correlation between the motivation of international students to study at U.S. institutions and their resilience in the face of potential academic and nonacademic challenges. We argue that both these factors (motivation and resilience) influence the adjustment and well-being of international students and their interplay helps to explain the retention of international students in U.S. HEIs.

\section{Motivation of International Students}

Motivation is an internal condition that directs, encourages, and sustains a certain behavior. Research into motivation focuses on how and why individuals pursue actions towards certain goals, how persistent they are in pursuing those goals, and what perceptions and beliefs they maintain and develop along the way (Biggs, 1987; Martin, 2002; Woolfolk, 2019). Intrinsic and extrinsic motivational factors explain individuals' behaviors. When a behavior is self-determined, the motivation behind it is referred to as intrinsic. Individuals are intrinsically motivated when they choose to pursue a certain activity to satisfy their own wishes (Link, 2019). Thus, IM is linked to interest and/or to feelings of pleasure and satisfaction produced directly from involvement in a certain activity. In contrast, a behavior or action taken 
instrumentally, as a means to produce a desired outcome, is referred to as extrinsic motivation (Link, 2019).

In the educational context, motivation can be defined as students' drive to learn and their resulting behavior (Martin, 2002). It is linked to students' learning approaches (Biggs, 1987). Students who have extrinsic motives to avoid failure, engage in surface learning strategies in order to acquire bare-essential knowledge and meet institutional requirements. Similarly, students with achievement motives (another extrinsic motive), which emerge from the exigencies of competition and ego fulfillment (Biggs, 1987), locus of control, academic achievement, and life satisfaction (Karaman \& Watson, 2017) tend to use achievement learning strategies and behave as model students in order to reach the highest ranks (Biggs, 1987). In contrast, students with IM tend to use deep learning strategies, such as reading widely and integrating new material with previous knowledge, to satisfy their interest in or desire for competence with particular content (Biggs, 1987). Motivation is also linked to students' achievement and retention. In a case study conducted by Martinez (2001), teachers and administrators interpreted their efforts to improve retention and achievement in relation to four motivational approaches: democratic, affective, cognitive, and social. Sharing responsibilities and decisions with students, consideration given to students' emotional development, development of students' learning skills, and cooperation with parents and peers to support students' development, were all approaches that teachers and administrators believed were critical for improving students' motivation (Martinez, 2001). In that sense, Martinez (2001) argues that "improving retention and achievement usually involves strategies to improve student motivation" (p. 23).

One of the primary factors that determine international students' decision to study in the United States is social mobility goals, such as the expectation of improving job opportunities and achieving upward class mobility (Hazen \& Alberts, 2006). Graduate and undergraduate international students pursue international education for career-related reasons, such as gaining work experience, planning their careers, and acquiring job search skills (Urban \& Palmer, 2016). For graduate students specifically, immigration and financial plans influence their drive to study in the United States (Zhou, 2015). The reputation of the United States as having high quality education that is globally respected (Chao et al., 2017; Miller, 2012), and the availability of paid scholarships, are equally important factors that contribute to international students' decision to study in the United States (Miller, 2012). Other factors related to personal growth - experiencing something new, learning about different cultures, gaining new perspectives on their own cultures, and meeting new people - also help explain international students' mobility (Chao et al., 2017; Lesjak et al., 2015).

Motivations tend to shift in certain ways as students pursue their degrees. According to Zhou (2015), the major motivations that assist international graduate students to persist in their academic endeavors fall into four categories: "(a) intrinsic interest in research; (b) intrinsic interest in teaching; (c) high utility value of a UStrained Ph.D.; and (d) high emotional and social cost of quitting" (p. 725). For the last motive, in particular, Zhou (2015) highlighted that the fear of failure remains influential in motivating students to overcome the various challenges they face, but 
also places significant pressure on their adjustment to the U.S. university setting (Zhou, 2015).

Gender also plays a role in the experience of international students. The motivations of female students are particularly rooted in the expectations they have about their experience in an American university (Saxena, 2014). Social expectations, such as the expectation of social support, increased social mobility, good studentteacher relationships, and expectation that they will develop effective professional networks in the United States play important roles in female students' academic motivations to pursue their degrees (Saxena, 2014).

Studies that investigate the motivations of international male students as a distinct group are limited in educational research. Rush (2013) evaluated gender, nationality, and generational/age influences on academic motivation, and demonstrated that females have higher IM than males. This difference in motivation between the genders also leads males and females to adopt different strategies to pursue their degrees.

\section{International Students' Resilience}

Resilience is an individual's ability to successfully adapt to challenges, threats, and shifting circumstances (Woolfolk, 2019). Resilient individuals perceive that there is always hope, despite any adverse experiences. They also tend to display unique characteristics in response to challenges, stress, and change, such as perseverance, self-reliance, and nonconformity; these personal characteristics empower individuals to overcome challenging events (Wagnild \& Collins, 2009). Often, resilient individuals are able to reflect on their experiences and thus identify and be aware of the inner strengths, competencies, and achievements that they have acquired over their lifetime (Wagnild \& Collins, 2009).

For students, personal life events influence their resilience. Although adverse life experiences have been linked to various negative outcomes, individuals with high resilience are less influenced by these adverse experiences, and more often function normally afterwards (Edwards et al., 2016). Gonçalves et al. (2017) showed that there is a significant positive relationship between the negative life events that students experience and their resilience. The researchers argued, "Higher frequency and impact of experienced negative events translates into higher resilience" (Gonçalves et al., 2017, p. 2390). The study conducted by Edwards et al. (2016) showed that "lack of adversity within the relationship with parents/guardians and an internal locus of control were found to predict higher levels of resilience" (p. 26). However, specific kinds of adverse life events have been negatively correlated with an individual's resilience. The explanation of when and why adverse events help or harm resilience is related to the meaning assigned to them, the nature of the event, available social support, and the individual's characteristics and adaptation strategies (Gonçalves et al., 2017). Moreover, previous studies (Stanley \& Bhuvaneswari, 2016) have shown a significant correlation between the resilience and coping/adjustment of students in the face of adverse situations.

Uncertainty about program admission in first-year undergraduate students and anxieties relating to career and employment in graduating students help explain the 
stress these students experience through college years (Stanley \& Bhuvaneswari, 2016). However, those with higher resilience tend to cope better with these stressors (Stanley \& Bhuvaneswari, 2016). For graduate students, Wang (2003) showed that among other factors, such as gender and country of origin, students' resilience plays an important role in predicting students' adjustment problems. Together, these factors - personal life events, locus of control, and degree level - have been shown to influence students' resilience in higher education. In order to tackle adjustment challenges for international students in U.S. higher education effectively, it is reasonable to have specially designed retention strategies for different student groups, based on an understanding of students' resilience and the institution's role in supporting the resilience of their students. Cotton et al. (2017) argued that understanding "what the university does and what the students do" (p. 77) can help higher education institutions understand their students' experiences and identify areas in which institutions can better support students.

\section{METHOD}

This study was approved by the Saint Louis University Institutional Review Board for research on human subjects. It investigated the relationships between three variables - IM, EM, and resilience - by measuring the degree of linear correlation between them (Aron et al., 2011). We aimed to investigate the following four research questions by employing this study's survey instrument. (a) What motivates international students to pursue their desired degree at U.S. universities? (b) What correlations are there between the motivations of international students and their resilience? (c) Are there any differences between female and male international students in terms of motivations and resilience? (d) Are there any differences between undergraduate and graduate international students in terms of motivation and resilience?

\section{Participants}

Following review board approval, a hyperlink to the study survey was distributed to 2,069 international students enrolled in three 4-year research institutions in the United States: Saint Louis University $(n=832)$, University of Missouri-St. Louis $(n$ $=541)$, and the University of Texas-San Antonio $(n=696)$, through the offices for international services at the students' universities. A minimum sample of $n=85$ was needed for power analysis for a two-tailed medium effect $(r=.30)$ with a significance level of 0.05 (Aron et al., 2011). A total of 164 participants completed all scales and provided data on their demographic backgrounds (a response rate of $7.9 \%$ ). The sample size $(n=164)$ was within the methodological requirements needed for $80 \%$ power in testing a hypothesis at the 0.05 significance level (Aron et al., 2011). Of the 164 participants in the survey, $66(40.49 \%)$ were male and $97(59.51 \%)$ were female, with an average age of 26.5 years $(S D=6.53$; range $=18-51)$. Fifty-three percent of participants were 18 to 25 years old (inclusive), and $47 \%$ were above 25 years old. A total of $105(64 \%)$ were graduate students, and $59(36 \%)$ were undergraduate students. Of the undergraduate students, $14(23.7 \%)$ were first-year students, 17 
(28.8\%) were sophomores, 12 (20.34\%) were juniors, and 16 (27.12\%) were seniors. Participants came from different countries; $25 \%$ were from China, $7 \%$ from India, $7 \%$ from Saudi Arabia, $6 \%$ from Mexico, $5 \%$ from Thailand, $4 \%$ from South Korea, $4 \%$ from Spain, and none of the other countries contributed $4 \%$ or more of the participants.

\section{Instrumentation}

The survey used in this study consolidated The University Student's Motivation \& Satisfaction Questionnaire (TUSMSQ2; Neill, n.d.) and the Acculturation and Resilience Scale (AARS; Khawaja et al., 2014). The 18 motivation items from the TUSMSQ2 are sorted into two categories of motivation factors: intrinsic (selfexploration and altruism) and extrinsic (rejection of alternative options, career and qualifications, social enjoyment, and social pressure). The satisfaction items in the TUSMSQ2 were not used because they do not reflect the scope of this study. The content validity of the TUSMSQ2 items were reviewed by an expert, who is a professor of sociology and research methodology. The AARS was used to assess the resilience factor, which consists of 14 items that concern problem-solving, coping, personal strength, confidence, openness to adaptation, and optimistic attitude to life in a new place. The resilience factor (Factor 1) in the AARS has acceptable reliability, with Cronbach's $\alpha$ of 0.89 (Khawaja et al., 2014). Participants used a 5-point Likert scale to respond to the survey items, ranging from 1 (Does not describe me) to 5 (Describes me extremely well) for the motivation and resilience items. Higher scores indicate that respondents have higher levels of motivation or resilience respectively.

\section{RESULTS}

The results of descriptive statistics demonstrate that almost $66 \%$ of the participants reported being motivated to attend their universities for personal growth and development (an intrinsic motive). In addition, the relationships between the three variables - IM, EM, and resilience - were investigated using the Pearson productmoment correlation coefficient. As shown in Table 1, the results show that there was a weak, positive relationship between the means of EM and resilience $(r=.159, n=$ 123), and a moderate, positive relationship between the means of perceived IM and resilience $(r=.377, n=123, p<.01)$. These results suggest that high levels of IM are associated with high levels of resilience. With regard to the latter relationship (IM and resilience), the coefficient of determination between the variables was $14 \%$, indicating that IM helps explain $14 \%$ of the variance in respondents' scores for selfperceived resilience.

\section{Table 1: Pearson Product-Moment Correlations Between Measures of Perceived Motivations And Resilience}

\begin{tabular}{lccc}
\hline Variable & 1 & 2 & 3 \\
\hline Intrinsic motivation & - & $0.349^{*}$ & $0.377^{*}$ \\
Extrinsic motivation & - & - & 0.159 \\
Resilience & - & - & -
\end{tabular}


Note. ${ }^{*}$ Correlation is significant at the 0.01 level (two-tailed).

The researchers then conducted two independent-samples $t$ tests among the three variables in order to compare the differences between male and female students (Table 2) and between graduate and undergraduate students (Table 3 ). The results show a significant difference $(p=.06)$ in IM scores between males $(M=26.1, S D=$ 5.7) and females $(M=28.7, S D=4.5)$ with a moderate magnitude in the difference of means $\left(\eta^{2}=.06\right.$; Table 2$)$. These results suggest that international female students had higher IM than international male students. There was also a significant difference $(p=.064)$ in EM scores between graduate students $(M=36.28, S D=8.08)$ and undergraduate students $(M=40.56, S D=7.71)$ with a moderate magnitude of difference $\left(\eta^{2}=.064\right)$, indicating that undergraduate students had higher EM than graduate students. No significant differences were found between males and females in the EM-resilience relationship or between graduate and undergraduate students in the IM-resilience relationship.

Table 2: Results of $t$ Tests and Descriptive Statistics for Intrinsic Motivation, Extrinsic Motivation, and Resilience by Gender

\begin{tabular}{|c|c|c|c|c|c|c|c|c|}
\hline \multirow[b]{2}{*}{ Variable } & \multicolumn{2}{|c|}{ Males } & \multicolumn{2}{|c|}{ Females } & \multirow[b]{2}{*}{$t$} & \multirow[b]{2}{*}{$p$} & \multirow[b]{2}{*}{$95 \% \mathrm{CI}$} & \multirow[b]{2}{*}{$\eta^{2}$} \\
\hline & $M$ & $S D$ & $M$ & $S D$ & & & & \\
\hline $\begin{array}{l}\text { Intrinsic } \\
\text { motivation }\end{array}$ & 26.17 & 5.7 & 28.79 & 4.5 & -2.83 & 0.006 & $\begin{array}{l}{[-4.5} \\
-0.8]\end{array}$ & 0.06 \\
\hline $\begin{array}{l}\text { Extrinsic } \\
\text { motivation }\end{array}$ & 36.96 & 7.2 & 38.4 & 8.8 & -1.07 & 0.285 & $\begin{array}{c}{[-4.2,} \\
1.2]\end{array}$ & 0.008 \\
\hline Resilience & 56.2 & 8.7 & 57.1 & 8.9 & -0.56 & 0.57 & $\begin{array}{c}{[-4.1,} \\
2.3]\end{array}$ & 0.003 \\
\hline
\end{tabular}

Note. Equal variances not assumed.

Table 3: Results of $t$ Tests and Descriptive Statistics for Intrinsic Motivation, Extrinsic Motivation, and Resilience by Degree Level

\begin{tabular}{lcccccccc}
\hline & \multicolumn{9}{c}{ Graduate } & \multicolumn{2}{c}{ Undergraduate } & & & & \\
\cline { 2 - 5 } Variables & $M$ & $S D$ & $M$ & $S D$ & $t$ & $p$ & $95 \%$ CI & $\eta^{2}$ \\
\hline $\begin{array}{l}\text { Intrinsic } \\
\text { motivation* }\end{array}$ & 27.98 & 5.22 & 27.54 & 5.04 & 0.49 & 0.63 & {$[-1.34$,} & 0.002 \\
$\begin{array}{l}\text { Extrinsic } \\
\text { motivation* }\end{array}$ & 36.28 & 8.08 & 40.56 & 7.71 & -3.08 & 0 & $\begin{array}{r}{[-2.22]} \\
-7.03,\end{array}$ & 0.064 \\
Resilience** & 57.05 & 7.7 & 56.28 & 10.51 & 0.47 & 0.63 & $\begin{array}{r}-1.52] \\
{[-2.46,}\end{array}$ & 0.001 \\
& & & & & & & $4.00]$ & \\
\hline
\end{tabular}

Note. *Equal variances assumed for intrinsic and extrinsic motivation. **Equal variances not assumed for resilience. 


\section{DISCUSSION AND CONCLUSIONS}

The current study found that personal growth and development are important motives for international students to study in the United States. Further, this study found that international students in the United States who score higher on IM are more likely to score higher on resilience. These findings suggest that students who are intrinsically driven to satisfy their own educational aspirations are more likely to be psychologically equipped with resilience traits that allow them to overcome the various challenges associated with being international students at U.S. universities. These results are consistent with previous findings that self-determined and personal development motivations explain international students' adjustment, mobility, and success in new settings (Chirkov et al., 2008; Lesjak et al., 2015). This might be because self-determined motivations are associated with protective factors against the adversity that results from students' acculturation, resulting in, for example, a lower level of culture shock, more social engagement, and greater contextual subjective well-being (Yang et al., 2017). We do not claim that only intrinsically motivated students have resilience traits. Social mobility, career advancement, scholarships, the reputation of HEIs, and immigration intentions (Chao et al., 2017; Hazen \& Alberts, 2006; Miller, 2012; Urban \& Palmer, 2016; Zhou, 2015) all play significant roles in students' choices to study or continue studying in the United States. However, these extrinsic motives alone do not explain students' ability to overcome the communication, social, financial, academic, and psychological challenges they will experience in American institutions of higher education (Amirali \& Bakken, 2015; Hwang et al., 2014).

Further, female students reported a significantly higher level of IM compared with their male peers; this finding corroborates previous research by Saxena (2014) and Rush (2013). No significant difference was found between undergraduate and graduate students for IM; however, undergraduate students had higher EM than graduate students. The latter result is consistent with research by Lu and Adler (2011), where two of the top three reasons that international students choose to study in the United States - seeking a new and exciting experience, finding improved job prospects, and seeking better education-were related to extrinsic motives.

\section{IMPLICATIONS}

HEIs could support and retain international students by continuously fine-tuning retention strategies in the light of findings such as these. Retention strategies could be developed based on the knowledge generated about motivation and resilience. On the one hand, understanding international students' motivations allows HEIs to facilitate positive adjustment (Yang et al., 2017) and deliver more of the positive experiences (Ortiz \& Choudaha, 2014) that motivate these students to overcome the various challenges they face. Previous studies (Chao et al., 2017; Miller, 2012) agree that many international students are motivated to attend HEIs in the United States because of the "reputation of the US as having a higher education experience that will be respected by others in the marketplace and globally" (Miller, 2012, p. 221). Thus, positive learning environments that are delivered through HEIs' democratic and 
affective efforts to consider students' motivations ("improving retention and achievement usually involves strategies to improve student motivation"; Martinez, 2001 , p. 23) will certainly help them to attract and retain diverse groups of international students.

On the other hand, Cotton et al. (2017) stated that developing students' resilience assists in their retention as it "acts as a protective factor" against adversity and helps "all students to access the transformational learning opportunities which HE offers" (p. 77). Institutional support can be provided in the form of outreach counseling (Hwang et al., 2014) and workshops (Rubin, 2014) that address issues related to the motivations and resilience of students. Positive engagement experiences could potentially benefit international students in terms of retention (Martinez, 2001); therefore, these workshops could entail cross-campus collaboration (Pidgeon et al., 2014; Rubin, 2014) between different stakeholders such as international student organizations, faculty, and student affairs, across a wide variety of motivational approaches (Martinez, 2001). This would assist international students to overcome the various challenges they experience both on and off campus (Miller, 2012; Yan \& Pei, 2018). Pidgeon et al. (2014) demonstrated that "students with low levels of resilience reported significantly lower levels of perceived social support and campus connectedness and higher levels of psychological distress, in comparison to university students with high levels of resilience" (p. 14).

Therefore, cross-campus collaboration between counseling centers and other campus departments could nurture the well-being of international students (Hwang et al., 2014). Optimally, such retention strategies would promote students' efforts to sustain and advance American higher education's globalization efforts and embrace of diversity in higher education.

\section{Study Limitations and Future Research}

The study sample was drawn from only three universities located in the midwest and west south-central regions of the United States. The findings may therefore be only a representation of the motivations and resilience traits of international students within these areas. Future research could extend the findings of this study and examine the motivations and resilience of international students in other regions of the United States. We hypothesize that international students in different areas, such as the western states, which contain many people from minority groups, may have different motives for studying in the United States and possess different resilience traits.

Furthermore, while the analysis suggests some common psychological characteristics among international students related to motivational orientations and resilience, differences among cultural groups have not been the focus of this study. Banks (2013) argued that cultural differences among students can serve as a powerful explanation of differences in the characteristics of their learning approaches and suggest ways to teach them. We believe that future qualitative research that examines the experiences of students from different cultural groups could provide educational researchers with an in-depth understanding of why these students are motivated to study in the United States and how they are differently affected by the academic and 
nonacademic challenges they face. Ultimately, comparative research on the affairs of international students can advance current knowledge by allowing the formulation of generalizable theories (Arnove et al., 2013) about the dynamics of international students' mobility —in particular, their motivations, resilience traits, and interactions with their educational environments.

\section{REFERENCES}

Amirali, S., \& Bakken, J. P. (2015). Trends and challenges of recruiting and retaining international graduate students: An internal perspective. Journal of Education Research, 9(4), 425-433.

Arnove, R., Torres, C. A., \& Franz, F. (2013). Comparative education: The dialectic of the global and the local (4th ed.). Rowman \& Littlefield Publishers.

Aron, A., Coups, E. J., \& Aron, E. N. (2011). Statistics for the behavioral and social sciences (5th ed.). Pearson Education.

Banks, J. A. (2013). The construction and historical development of multicultural education, 1962-2012. Theory into Practice, 52(1), 73-82.

Biggs, J. (1987). Student approaches to learning and studying. Australian Council for Educational Research.

Bowman, N., \& Park, J. (2014). Interracial contact on college campuses: Comparing and contrasting predictors of cross-racial interaction and interracial friendship. The Journal of Higher Education, 85(5), 660-690.

Chang, M. J. (1999). Does racial diversity matter? The educational impact of a racially diverse undergraduate population. Journal of College Student Development, 40(4), 377-393.

Chang, M. J., Denson, N., Sáenz, V., \& Misa, K. (2006). The educational benefits of sustaining cross-racial interaction among undergraduates. The Journal of Higher Education, 77(3), 430-455.

Chao, C., Hegarty, N., Angelidis, J., \& Lu, V. F. (2017). Chinese students' motivations for studying in the United States. Journal of International Students, $7(2), 257-269$.

Chirkov, V., Safdar, S., De Guzman, J., \& Playford, K. (2008). Further examining the role motivation to study abroad plays in the adaptation of international students in Canada. International Journal of Intercultural Relations, 32(1), 427-440.

Chow, B. (2019). Multiculturalism. Salem Press Encyclopedia.

Cotton, D., Nash, T., \& Kneale, P. (2017). Supporting the retention of non-traditional students in higher education using a resilience framework. European Educational Research Journal, 16(1), 62-79.

Edwards, T., Catling, J., \& Parry, E. (2016). Identifying predictors of resilience in students. Psychology Teaching Review, 22(1), 26-34.

Franklin, R. S. (2013). The roles of population, place, and institution in student diversity in American higher education. Growth \& Change, 44(1), 30-53.

Gonçalves, A. M., Cabral, L. R., Ferreira, M. C., Martins, M. C., \& Duarte, J. C. (2017). Negative life events and resilience in higher education students. The European Journal of Social and Behavioral Sciences, 19(2), 2381-2392. 
Guo, S., \& Jamal, Z. (2007). Nurturing cultural diversity in higher education: A critical review of selected models. Canadian Journal of Higher Education, 37(3), $27-49$.

Hazen, H. D., \& Alberts, H. C. (2006). Visitors or immigrants? International students in the United States. Population, Space, and Place, 12, 201-216.

Hwang, B. J., Bennett, R., \& Beauchemin, J. (2014). International students' utilization of counseling services. College Student Journal, 48(3), 347-354.

Institute of International Education. (2018). International student enrollments by institutional type, 2016/17-2017/18 [Data set]. Open Doors Report. https://www.iie.org/Research-and-Insights/Open-Doors/Fact-Sheets-andInfographics/Infographics/International-Student-Data

Johnson, M., \& Banks, R. (2017). Diversity matters in international education. International Educator, 26(1), 54-55.

Karaman, M. A., \& Watson, J. C. (2017). Examining associations among achievement motivation, locus of control, academic stress, and life satisfaction: A comparison of US and international undergraduate students. Personality and Individual Differences, 111(1), 106-110.

Khawaja, N., Moisuc, O., \& Ramirez, E. (2014). Developing an acculturation and resilience scale for use with culturally and linguistically diverse populations. The Australian Psychological Society, 49, 171-180.

Lesjak, M., Juvan, E., Ineson, E., Yap, M., \& Axelsson, E. (2015). Erasmus student motivation: Why and where to go? Higher Education, 70(5), 845-865.

Link, S. (2019). Self-determination theory. Salem Press.

Lu, T. Y., \& Adler, H. (2011) Perspectives of international undergraduate students in hospitality and tourism management programs in the United States: Implications for educators and administrators. Journal of Hospitality \& Tourism Education, $23(3), 16-25$.

Martin, A. (2002). Motivation and academic resilience: Developing a model for student enhancement. Australian Journal of Education, 46(1), 34-49.

Martinez, P. (2001). College improvement: The voice of teachers and managers. Learning and Skills Development Agency. http://dera.ioe.ac.uk/id/eprint/9955

Miller, R. S. (2012). Understanding the motivation of Vietnamese international students and their higher education experiences in the United States (Publication no. 3533594) [Doctoral dissertation, University of North Texas]. ProQuest Dissertations \& Theses Global.

Neill, J. (n.d.). The university student motivation and satisfaction questionnaire version $2 . \quad$ Retrieved from wilderdom.com/courses/surveyresearch/assessment/labreport/TUSMSQ2.doc

Ortiz, A., \& Choudaha, R. (2014). Attracting and retaining international students in Canada. World Education News + Reports. http://wenr.wes.org/2014/05/attracting-and-retaining-international-students-incanada

Pidgeon, A. M., Rowe, N. F., Stapleton, P., Magyar, H. B., \& Lo, B. C. (2014). Examining characteristics of resilience among university students: An international study. Open Journal of Social Sciences, 2, 14-22. 
Rubin, K. (2014). Retaining international students. International Educator, 23(5), $30-37$.

Rush, K. (2013). A quantitative evaluation of gender, nationality, and generational/age influence on academic motivation (Publication No. ED555995) [Doctoral dissertation, Northcentral University]. ProQuest Dissertations \& Theses Global..

Saxena, S. (2014). International graduate women students in America: Motivations and expectations. Women in Higher Education, 23(12), 18-19.

Siczek, M. (2015). Developing global competency in US higher education: Contributions of international students. The CATESOL Journal, 27(2), 5-21.

Stanley, S., \& Bhuvaneswari, M. G. (2016). Stress, anxiety, resilience and coping in social work students (a study from India). Social Work Education, 35(1), 78-88.

Urban, E., \& Palmer, L. (2016). International students' perceptions of the value of US higher education. Journal of International Students, 6(1), 153-174.

Valentine, K., Prentice, M., Torres, M. F., \& Arellano, E. (2012). The importance of student cross-racial interactions as part of college education: Perceptions of faculty. Journal of Diversity in Higher Education, 5(4), 191-206.

Wagnild, G., \& Collins, J. (2009). Assessing resilience. Journal of Psychosocial Nursing \& Mental Health Services, 47(12), 28-33.

Wang, J. (2003). A study of the adjustment of international graduate students at American universities, including both resilience characteristics and traditional background factors (Publication No. 305326526) [Doctoral dissertation, Florida State University]. ProQuest Dissertations \& Theses Global.

Williams, D. A. (2013). Strategic diversity leadership: Activating change and transformation in higher education. Stylus Publishing.

Woolfolk, A. (2019). Educational psychology (14th ed.). Pearson Education.

Yan, L., \& Pei, S. (2018). Home away from home. How international students handle difficult and negative experiences in American higher education. Journal of International Students, 8(1), 453-472.

Yang, Y., Zhang, Y., \& Sheldon, K. M. (2017). Self-determined motivation for studying abroad predicts lower culture shock and greater well-being among international students: The mediating role of basic psychological needs satisfaction. International Journal of Intercultural Relations, 63(1), 95-104.

Zhou, J. (2015). International students' motivation to pursue and complete a Ph.D. in the US. Higher Education, 69(5), 719-733.

HEBA MOSTAFA, PhD, was born in Cairo, Egypt. Heba immigrated to the United States in 2011. She received a $\mathrm{PhD}$ in Educational Foundations at Saint Louis University (SLU). She has served as a graduate research and teaching assistant in the School of Education at SLU. During her assistantship, she co-taught courses in multicultural and global literature. She served as an invited lecturer in School of Education classes at SLU and presented at various national educational conferences. Heba was the 2016 recipient of the Dr. Carol Kahler Scholarship and was awarded second place for the paper she co-presented at SLU's 2017 Graduate Research Symposium. Heba is pursuing a career in college teaching in the United States. Her 
research interest lies in studying diversity issues in higher education, with specific focus on the phenomenon of acculturation and its relation to cross-cultural competency and multiple identities of minority student groups. Her dissertation research focused on the acculturation and bicultural identities of second-generation Asian Indian American undergraduates. Email: drhebamostafa5@gmail.com

LOELLE (YONGSUN) LIM, PhD, was born in Seoul, South Korea. Loelle has an extensive background in education-related subjects: Loelle received $\mathrm{PhD}$ in higher education administration at Saint Louis University, has a master's degree in TESOL, obtained her bachelor's degree in mathematics at Daejun University in South Korea, and is an education specialist with a degree in English education from the University of Missouri-Columbia. With her 17-year teaching career, Loelle's professional expertise lies in international students' acculturation process, multicultural diversity issues, and teaching Korean and English as a foreign language. Loelle is currently serving as an Assistant Professor of Korean language in Defense Critical Language and Culture Program at the University of Montana. Email: Yongsun.lim@umt.edu 